GANIT J. Bangladesh Math. Soc. (ISSN 1606-3694) 34 (2014) 75-87

\title{
SUPPLY CHAIN OPTIMIZATION BY MIXED INTEGER PROGRAM FOR MANUFACTURER AND RETAILER SYSTEM OF POULTRY FIRM IN BANGLADESH
}

\author{
Mohammad Khairul Islam ${ }^{1}$, Mohammed Forhad Uddin ${ }^{2}$ and Md. M. Alam \\ ${ }^{1}$ Department of Mathematics, Tongi Government College, Gazipur, Bangladesh. \\ 2 Department of Mathematics, Bangladesh University of Engineering and Technology (BUET) \\ ${ }^{3}$ Department of Mathematics, Dhaka University of Engineering and Technology (DUET) \\ E-mail: ${ }^{1}$ khairulamc@ gmail.com, ${ }^{2}$ kforhad77@gmail.com, ${ }^{3}$ alamdr.mahmud@yahoo.com
}

Received 12.10.2014 Accepted: 11.01.2015

\begin{abstract}
In this study, we formulate mixed integer program for manufacturer and retailer system of poultry firm in Bangladesh that is one of the most promising sectors to increase Gross Domestic Product (GDP) growth rate plus equitable distribution through arranging food security as well as ensuring self-employment, creating purchasing power and reducing poverty at a large scale. From the survey, it has observed that the selling price of eggs and chicken fluctuate depending on the natural calamities. We have made a question survey on some poultry firm in the district of Mymensingh and Gazipur. This paper maximized the profit and minimizes the cost. The formulated mixed integer program has solved by branch and bound algorithm using A Mathematical Programming Language (AMPL). It has observed that the profit and selling price have very good relationship with production cost and raw materials cost but no significant relation with fixed cost.
\end{abstract}

Keywords : Poultry, Price, Prospect, Supply chain management, Mixed integer program, Optimization, Linear programming

\section{Introduction}

In the global competition market, the importance of Supply Chain Management (SCM) is increasing day to day. Maximize the profit and minimize the cost are the main factors that play an important role in supply chain. Further, it is important to make the model optimal for both consumer as well as manufacturer. In this paper, a mixed-integer programming (MIP) model is derived to determine the sites for manufacturer and the best allocation for both the retailer and manufacturer. Coordination among the members of supply chain is one of the vital issues to overcome the new challenges of the comprehensive enterprise. Without coordination, a supply chain system could not be optimal as a whole since each party always try to enhance his own profits only. That is why to ensure the optimal system and to satisfy customer demands in today's competitive markets; significant information needs to be shared along the supply chain. And a high level of coordination between manufacturer's and retailer's decision making is also required.

Supply chain is the strategic positioning of the manufacturing facilities, warehouses and distribution centers. Canel and Khumawala [1] provide a review of the literature for the incapacitated multi-period international facilities location problem (IFLP). They 
formulate a MIP model and solve it using the branch and bound method. The decision variables include the countries to locate manufacturing facilities, and their production and shipping levels. They also provide a case study with an application of the solution procedure. Canel et al. [2] later develop heuristic procedures for solving the MIP model of a similar IFLP. The heuristic procedures are tested for their computational efficiency. The profit maximization problem also considers the other important factors for international location problems, such as, exchange rates, export incentives, tariffs, taxes, and so on. The multi-period model also takes into account the time-dependent variations in prices, costs, and demands. Cohen and Lee [3] develop an analytical model to establish materials requirements policy based on stochastic demand. They develop four different sub-models with a minimum-cost objective. A mathematical algorithm at the end decides the optimal ordering policies to minimize the costs. Cohen and Lee [4] also develop a deterministic analytical MIP model to maximize the global after-tax profits through optimal policies for facility network design and material flows. The decision variables for the network design issues include location and capacities of all production facilities whereas those for material management issues include sourcing decisions, production and distribution planning. The model decides the optimal resource deployment for a particular policy option. It thus shows the robustness of the global manufacturing network which provides the company with increased flexibility in responding to changing scenarios by adjusting the sourcing, production, and distribution plans.

A MIP model for a production, transportation, and distribution problem has been developed by Pirkul and Jayaraman [5] to represent a multi-product tri-echelon capacitated plant and warehouse location problem. The model minimizes the sum of fixed costs of operating the plants and warehouses, and the variable costs of transporting multiple products from the plants to the warehouses and finally to the customers. A solution procedure is provided based on Lagrangian relaxation (LR) to find the lower bound, followed by a heuristic to solve the problem. The research shows computationally stable results for this combined approach. The heuristic, in particular, performs well with respect to approximations of optimality and solution times. Fumero and Vercellis [6] also use LR to solve a MIP model for integrated multi-period optimization of production and logistics operations. Chandra and Fisher [7] compare the computational aspects of solving the production and distribution problems separately and in a combined model. A number of cases with different values for the various parameters for these models are analyzed to compare the performances. These parameters include duration of planning period, number of products, number of customer, fixed costs, inventory costs etc. A cost minimization model is developed along with constraints to present the problem in its integrated form.

The concept of Joint Economic Lot Sizing (JELS) has been introduced to filter traditional methods for independent inventory control and to find a more profitable joint production and inventory policy. Qin et al. [8] have considered volume discounts and franchise fees as coordination mechanism in a system of supply chain with single supplier and single buyer with price sensitive demand. Subsequently, they showed that when demand is price 
sensitive, channel profits achieved by employing volume discounts and franchise fees is larger than achieved by quantity discounts and franchise fees. Uddin and Sano [9] developed an MIP based vendor-buyer multiple products-consumers, facility selection problem with a price-sensitive linear demand function. They assumed that by coordinated mechanism among the members of supply chain could achieve the optimal solution and the optimal location for the warehouse. Consequently, Uddin and Sano explained an MIP based a supply chain with a coordination mechanism consisting of a single vendor and buyer is considered. Pourakbar et al. [10] descried an integrated four-stage supply chain system, incorporating one supplier, multiple producers, multiple distributors and multiple retailers. Then they determined the optimal order quantity of each stage and shortage level of each stage to minimize the cost of the supply chain. Wu and Yen [11] have provided some patch works to enhance the volubility of the integrated single-vendor single-buyer inventory model. Zavanella and Zanoni [12] have investigated the Consignment Stock (CS) policy on Vendor-Managed Inventory (VMI) model and showed that CS policy is works better than the uncoordinated optimization and is implemented for an industrial case of a single-vendor and multiple-buyer production situation. Jokar and Sajadieh [13] have described a vendor-buyer integrated production inventory model considering Joint Economic Lot Sizing (JELS) policy with price sensitive linear demand of the customer. Qi et al. [14] described supply chain coordination with demand disruption. In their model, the market demand function is assumed to be a linear function of the retail price, $\mathrm{Q}=\mathrm{D}-\mathrm{kp}$, where $\mathrm{D}$ is maximum market demand, $\mathrm{p}$ is the retail price, $\mathrm{k}$ is a coefficient of price sensitivity, and $Q$ is the real demand under retail price $p$.

Akter and Uddin [15] argue that as an important sub sector of livestock production, the poultry industry in Bangladesh plays a vital role in economic growth and simultaneously creates numerous employment opportunities. The poultry industry, as a fundamental part of animal production, is committed to supply the nation which a cheap source of good quality nutritious animal protein in terms of meat and eggs. Islam, Uddin and Alam [16] analyze challenges and prospects of poultry industry in Bangladesh by using data collection from some important poultry industry. Andrew et al. [17] marketing systems play a decisive role in vibrant economies as mechanisms for both exchange (necessary for specialization and hence leads to higher economic growth) functions and the proper coordination of the exchange (through price signals) which reflect and shape producer and consumer incentives in supply and demand interaction. If small scale domestic producers are to take advantage of the projected domestic demand growth, then marketing systems in the supply chains linking producers to consumers must be able to support low cost production and timely delivery of the products.

The reminder of this paper is organized as follows. In Section 2, a mathematical formulation of the model MIP is presented. The section has four subsections which describe the concept of mixed integer linear fractional programming problem, notations, assumption, prerequisites and finally the MIP model. In Section 3, data collection, solution and the results of these models are discussed. Finally, in Section 4, the conclusions and contributions of this study are discussed. 


\section{Formulation}

In this section, we have described the notations, assumptions and model formulation.

\subsection{Notations and Assumptions}

Table 1. Notation for the multiproduct multicustomer and multi-facility manufacturer-retailer system

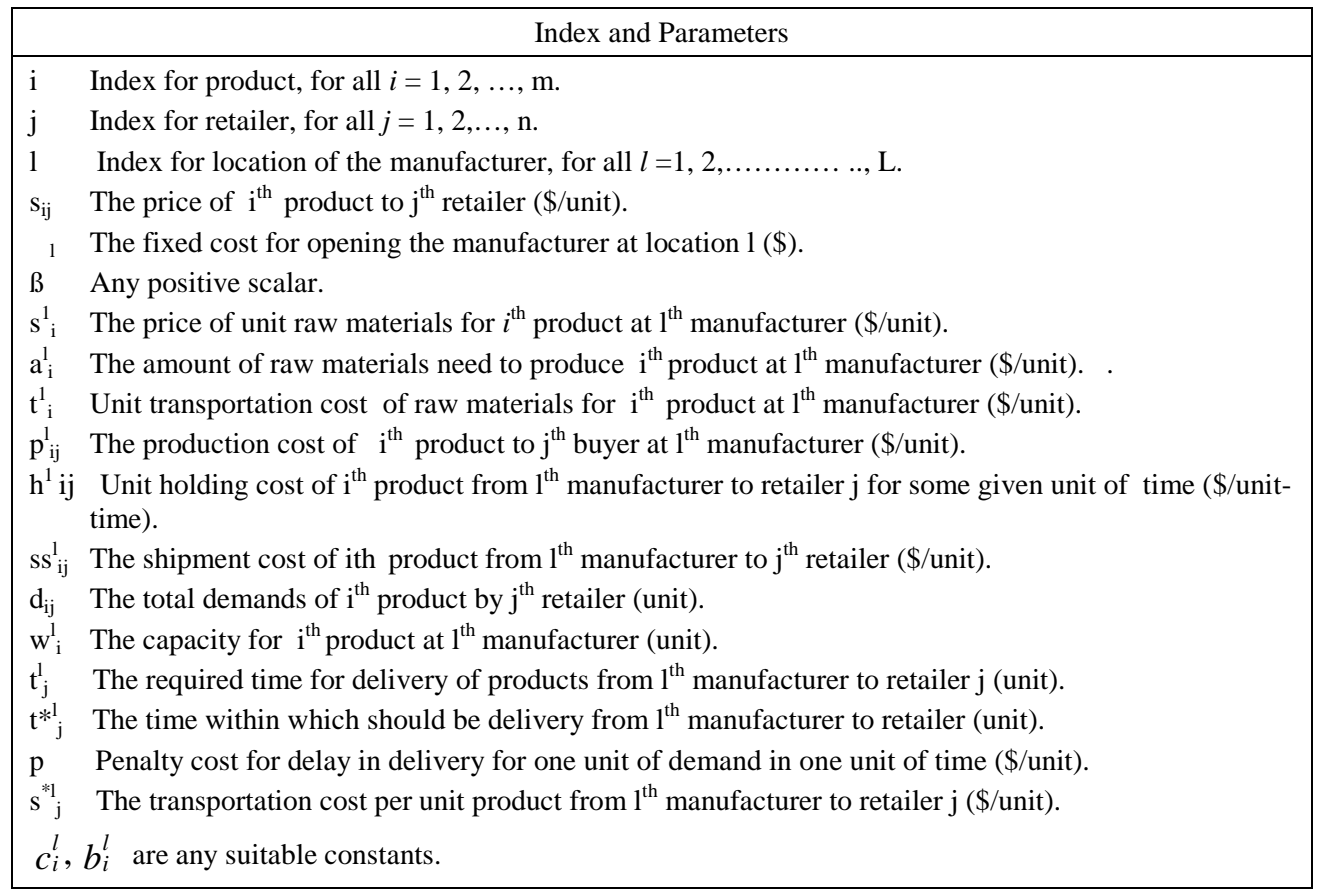

\section{Penalty defining function}

The function could be defined as

$g^{l}{ }_{j}=\left\{\begin{array}{l}1, \text { if } t^{l}{ }_{j}>t^{* l}{ }_{j}, \\ 0, \text { else }\end{array}\right.$, where $\mathrm{t}_{\mathrm{j}}^{1}$ is the required time for delivery of products from $1^{\text {th }}$ manufacturer to retailer $\mathrm{j}$ and $\mathrm{t}^{* 1}{ }_{\mathrm{j}}$ is the time within which should be delivery from $\mathrm{l}^{\text {th }}$ manufacturer to retailer.

\section{Decision Variables}

$$
\begin{aligned}
& y_{j}^{l}=\left\{\begin{array}{l}
1, \text { if customer } j \text { is assaign to manufacturer } l, \\
0, \text { else }
\end{array}\right. \\
& x_{l}=\left\{\begin{array}{l}
1, \text { if location l is used, } \\
0, \text { else }
\end{array}\right.
\end{aligned}
$$

$\mathrm{Q}_{\mathrm{ij}}^{1}=$ the production quantity of product $\mathrm{i}$ for retailer $\mathrm{j}$ at $\mathrm{l}^{\text {th }}$ manufacturer (unit). 


\section{Assumptions}

1. Each manufacturing facility is able to produce all of products.

2. The selling price for a product may vary from retailer to retailer depending on the discussions, order sizes, discounts, historical relationships, etc.

3. The company and retailer have agreed beforehand on the inventory distribution pattern so the shipping plans would be formulated accordingly.

\section{Prerequisites of the Objective Function}

Total return: $Z_{1}=\sum_{i=1}^{m} \sum_{j=l l}^{n} \sum_{j=1}^{L} Q_{i j}^{l} s_{i j}$

Fixed opening cost: $c 1=\sum_{l=1}^{L} x_{l} \alpha_{l}$

Input cost: $\quad c_{2}=\sum_{l=l}^{L} \sum_{i=1}^{m} s_{i}^{l} a^{l}{ }_{i}+\sum_{l=l i=1}^{L} \sum_{i=1}^{m} t_{i}^{l} a_{i}{ }_{i}$

Production cost: $\quad c_{3}=\sum_{l=1}^{L} \sum_{j=l}^{n} \sum_{i=1}^{m} Q^{l}{ }_{i j} p_{i j}$

Shipment cost: $\quad c_{4}=\sum_{l=1}^{L} \sum_{j=l}^{n} \sum_{i=1}^{m} Q^{l}{ }_{i j} s s^{l}{ }_{i j}$

Inventory holding cost: $c_{5}=\sum_{l=1}^{L} \sum_{j=l i=1}^{n} \sum_{i=1}^{m} Q^{l} h_{i j}^{l} / 2$

Penalty cost: $c_{6}=\sum_{l=}^{L} \sum_{j=1}^{n} p d_{i j} y_{j}^{l}\left(t^{l}{ }_{j}-t^{* l}{ }_{j}\right) g_{j}{ }_{j}$

Transportation cost: $c_{7}=\sum_{l=1}^{L} \sum_{j=1}^{n} t^{l}{ }_{j} s^{{ }^{*} l}{ }_{j}$

Linear demand function: $D(P), c_{8}=c_{i}^{l}+b_{i}^{l} * s_{i}^{l}$

\subsection{MIP model}

In this subsection, we formulate the MIP model considering the all prerequisites terms described previous subsection.

The objective function is:

$$
\text { Maximize }=Z_{1}-Z_{2}
$$

where, $Z_{1}$ is the total return,

$Z_{2}$ is the total investment $\left(c_{1}+\ldots+c_{8}\right)$ explained in previous subsection.

Therefore, MIP can be reformulated into two equivalent linear problems as follows: 
Maximize:

$$
\begin{aligned}
& \sum_{i=1}^{m} \sum_{j=l l=1}^{n} \sum_{l=1}^{L} Q^{l}{ }_{i j} S_{i j}-\sum_{l=1}^{L} x_{l} \alpha_{l}-\left(\sum_{l=l i=1}^{L} \sum_{i=1}^{m} s_{i}^{l} a^{l}{ }_{i}+\sum_{l=l i=1}^{L} \sum_{i=1}^{m} t_{i}{ }_{i} a_{i}\right)-\sum_{l=1}^{L} \sum_{j=l i=1}^{n} \sum_{i=1}^{m} Q^{l_{i j}} p^{l}{ }_{i j} \\
& -\sum_{l=1}^{L} \sum_{j=l i=1}^{n} \sum_{i j}^{m} Q^{l}{ }_{i j} s s^{l}{ }_{i j}-\sum_{l=1}^{L} \sum_{j=l i=1}^{n} \sum_{i=1}^{m} Q^{l}{ }_{i j} h_{i j}{ }_{i j} / 2-\sum_{l=}^{L} \sum_{j=1}^{n} p d_{i j} y_{j}^{l}\left(t^{l}{ }_{j}-t^{* l}{ }_{j}\right) g^{l}{ }_{j}-\sum_{l=1}^{L} \sum_{j=1}^{n} t^{l}{ }_{j} s^{* l}{ }_{j}
\end{aligned}
$$

Subject to

$$
\begin{aligned}
& \sum_{l=l i=l}^{L} \sum_{i=1}^{m} Q_{i j}^{l}=\sum_{i=1}^{m} d_{i j}, \forall j \\
& \sum_{l=1}^{L} \sum_{j}^{n} Q_{i j}^{l}=\sum_{j=1}^{n} d_{i j}, \forall i \\
& \sum_{l=l}^{L} Q^{l}{ }_{i j}=d_{i j}, \forall i, j \\
& \sum_{j=1}^{n} Q^{l}{ }_{i j} \leq w_{i}^{l} \forall i, l \\
& \sum_{j=l i=l}^{n} \sum_{i=1}^{m} Q_{i j} \leq \beta x_{l}, \forall l \\
& \sum_{l=l}^{L} y_{j}^{l}=1, \forall j \\
& c_{i}^{l}=b_{i}^{l} * s_{i}^{l}, \forall i
\end{aligned}
$$

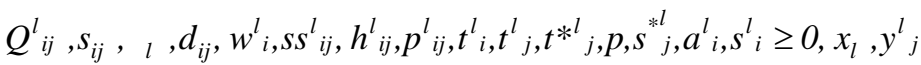

are binary $\forall i, j, l$

The objective function (1.1) estimates the difference between return and investment. Constraints (1.2) ensure that the total amount of products being manufactured at all plants for a particular retailer is equal to the total demand of that retailer. Similarly, constraints (1.3) guarantee that the total amount of a particular product being manufactured at all plants for all retailer is equal to the total demand of that product from all retailers. It is important to note here that the first two constraints are stated separately to show better accountability of the total demands from all retailers and for all products respectively. Constraints (1.4) assurance that the total amount of a specific product being manufactured for a particular retailer at all plants is equal to the demand of the specific product from that retailer. Constraints (1.5) present the capacity constraint. Constraints (1.6) premise that a plant is located when and only if there is a demand for any product. Constraints (1.7) show that each retailer is assigned to exactly one manufacturer. Equation (1.8) is the linear demand function. The last equation (1.9) is the nonnegative constraints. 


\section{Data Collection, Solution, Result and Discussion}

In this section, we have described data collections, solution procedure and result discussion.

\subsection{Data collection}

For this study both primary and secondary data sources were used. This study, primary data was collected by means of a questionnaire survey and interview with the poultry farmers in different poultry farms Mymensingh and Gazipur district of Bangladesh. Questions were asked to know the production cost and profit margin. In the first time the farmers had given their valuable data to complete the study. A basic problem in any analysis of the poultry sector relates to the lack of reliable and adequate data on use by type of feed and by category of poultry output, and on poultry population, disaggregated by scavenging and commercial birds. The study is largely based on information from secondary sources such as agricultural censuses and the FAO yearbook, different issues of statistical pocket book, Bangladesh bureau of statistics. Such information is supplemented by primary data generated from field surveys. In particular, the data on the current poultry production system, generated by the field surveys, have been used. Also, some data were collected from a rapid market survey including a few key-informant interviews. The following information collected from main poultry manufacturer and retailer in Mymensingh and Gazipur district.

Table 2. Parameters for MIP model

\begin{tabular}{|l|c|c|c|c|c|c|c|}
\hline \multicolumn{7}{|c|}{ Parameters } & \multicolumn{7}{c|}{ Locations of the vendor } \\
\hline & 1 & 2 & 3 & 4 & 5 & 6 & 7 \\
\hline Raw Materials (units) & $(0.5,30)$ & $(0.2,20)$ & $(0.5,30)$ & $(0.1,30)$ & $(0.1,20)$ & $(0.3,20)$ & $(0.4,30)$ \\
\hline TransCostRaw (input) & $(0.1,0.2)$ & $(0.2,0.2)$ & $(0.1,0.5)$ & $(0.1,0.3)$ & $(0.1,0.4)$ & $(0.2,0.3)$ & $(0.1,0.4)$ \\
\hline Production cost & $(2.0,120)$ & $(2.2,125)$ & $(2.1,130)$ & $(2.3,120)$ & $(2.2,130)$ & $(2.3,120)$ & $(2.1,125)$ \\
\hline Holding cost & $(0.1,1.2)$ & $(0.3,1.2)$ & $(0.3,1.4)$ & $(0.5,1.4)$ & $(0.2,1.3)$ & $(0.3,1.5)$ & $(0.4,1.3)$ \\
\hline Shipping cost & $(0.11 .3)$ & $(0.2,1.7)$ & $(0.3,1.6)$ & $(0.2,1.5)$ & $(0.2,1.5)$ & $(0.3,1.4)$ & $(0.4,1.2)$ \\
\hline Capacity(in hund.) units & $(700,750)$ & $(750,800)$ & $(900,700)$ & $(700,850)$ & $(850,700)$ & $(900,600)$ & $(800,750)$ \\
\hline Travel time units & $(10,8)$ & $(10,10)$ & $(12,10)$ & $(15,12)$ & $(10,10)$ & $(11,12)$ & $(12,10)$ \\
\hline Required Delivery time & $(5,7)$ & $(10,10)$ & $(12,8)$ & $(15,20)$ & $(10,10)$ & $(12,12)$ & $(14,10)$ \\
\hline Obligatory Delivery time & $(5,7)$ & $(10,10)$ & $(12,8)$ & $(15,20)$ & $(10,10)$ & $(12,10)$ & $(10,12)$ \\
\hline Trans. cost (/unit time) & $(0.1,1.7)$ & $(0.2,1.4)$ & $(0.3,1.5)$ & $(0.2,1.2)$ & $(0.1,1.5)$ & $(0.2,1.6)$ & $(0.3,1.5)$ \\
\hline DelaydefiningFun & $(0,0)$ & $(1,0)$ & $(0,0)$ & $(0,0)$ & $(0,0)$ & $(0,1)$ & $(0,0)$ \\
\hline Amountrawneed (in hund.) & $(130,120)$ & $(120,180)$ & $(150,200)$ & $(100,100)$ & $(100,100)$ & $(130,1200)$ & $(150,140)$ \\
\hline
\end{tabular}

Over the past two and half decades, price of meat and egg have increased four times. However, huge supply of poultry meat and egg helped keep the price at a relatively low 
level. During 1999-2000 and 2010-11, the price of broiler chicken had been stable at around 1.4 (\$.) per $\mathrm{kg}$, while the price of beef and mutton increased steadily which resulted in low relative price of chicken, which shows in Figure 1:

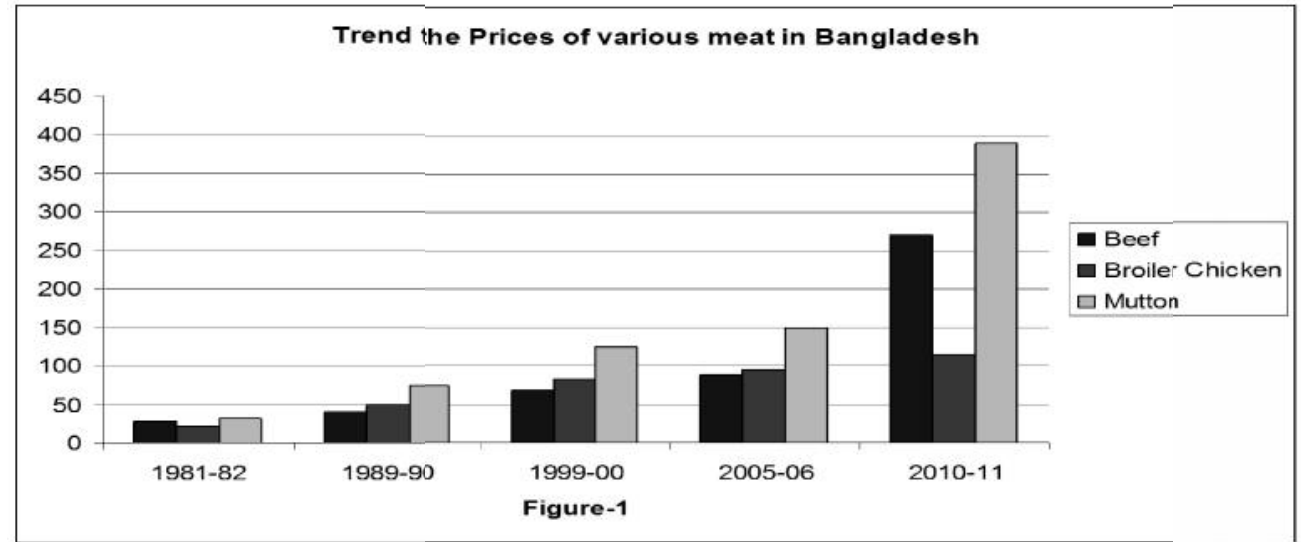

Source: Different Issues of Statistical Pocket Book, Bangladesh Bureau of Statistics.

According to the Bangladesh Poultry Industry Association, the price of a one-day-old broiler baby bird and the price of a one-day-old layer baby chick have increased, since the start of 2012, which shows in Figure 2:

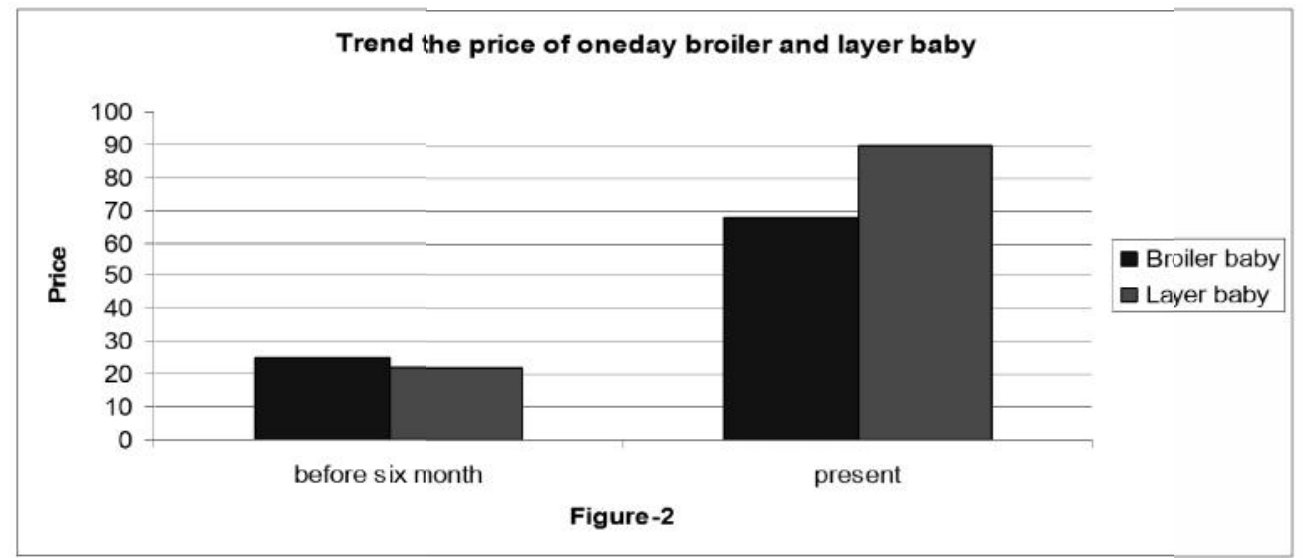

(Source: Financial Express)

\subsection{Solution procedure}

In order to solve the formulated MIP model, let the new decision could be redefined as follows:

$$
\begin{aligned}
& z_{l}=x_{l}, \text { for } l=1, \ldots, L \\
& z^{l}{ }_{j}=y^{l}, \text { for } j=1, \ldots, n, l=1, \ldots, L \\
& z^{l}{ }_{i j}=Q^{l}{ }_{i j}, \text { for } i=1, \ldots, m, j=1, \ldots, n, l=1, \ldots, L
\end{aligned}
$$


Since $y_{j}^{1}$ and $x_{1}$ are binary; as a result, $z_{1}$ and $z_{j}^{1}$ are become either zero or 1 . Further, since, $\mathrm{Q}_{\mathrm{ij}}^{1}$ is non-negative, consequently, $\mathrm{z}_{\mathrm{ij}}^{1}$ are also remaining non-negative. Therefore, MIP can be reformulated as follows:

Maximize:

$$
\begin{aligned}
& \sum_{i=1}^{m} \sum_{j=l l=1}^{n} \sum_{l}^{L} z_{i j}^{l} S_{i j}-\sum_{l=1}^{L} x_{l} \alpha_{l}-\left(\sum_{l=l i=1}^{L} \sum_{i}^{m} s_{i}^{l} a_{i}{ }_{i}+\sum_{l=l i=1}^{L} \sum_{i}^{m} t_{i}^{l} a_{i}^{l}\right)-\sum_{l=1}^{L} \sum_{j=l i=1}^{n} \sum_{i j}^{m} z_{i j} p_{i j} \\
& -\sum_{l=1}^{L} \sum_{j=l i=1}^{n} \sum_{i=1}^{m} z^{l}{ }_{i j} s s^{l}{ }_{i j}-\sum_{l=l}^{L} \sum_{j=l i=1}^{n} \sum_{i j}^{m} z^{l}{ }_{i j} h_{i j}^{l} / 2-\sum_{l=}^{L} \sum_{j=1}^{n} p d_{i j} y^{l}{ }_{j}\left(t^{l}{ }_{j}-t^{* l}{ }_{j}\right) g^{l}{ }_{j}-\sum_{l=1}^{L} \sum_{j=1}^{n} t^{l}{ }_{j} s^{* l}{ }_{j}
\end{aligned}
$$

Subject to

$$
\begin{aligned}
& \sum_{l=l i=l}^{L} \sum_{i=l}^{m} z_{i j}^{l}=\sum_{i=l}^{m} d_{i j}, \forall j \\
& \sum_{l=1}^{L} \sum_{j}^{n} z_{i j}^{l}=\sum_{j=1}^{n} d_{i j}, \forall i \\
& \sum_{l=1}^{L} z_{i j}^{l}=d_{i j}, \forall i, j \\
& \sum_{j=l}^{n} z_{i j}^{l} \leq w_{i}^{l} \forall i, l \\
& \sum_{j=l i=l}^{n} \sum_{i j}^{m} z^{l} \leq 10000 z_{l}, \forall l \\
& \sum_{l=1}^{L} z_{j}^{l}=1, \forall j \\
& \sum_{l=1}^{L} z_{l} \alpha_{l}+\sum_{l=l i=1}^{L} \sum_{i}^{m} t^{l}{ }_{i} d_{i}+\sum_{l=l i=1}^{L} \sum_{i=1}^{m} s_{i}{ }_{i} a^{l}{ }_{i}+\sum_{l=1}^{L} \sum_{j=l i=1}^{n} \sum_{i=1}^{m} z^{l}{ }_{i j} p^{l}{ }_{i j}+\sum_{l=1}^{L} \sum_{j=l i=1}^{n} \sum_{i=1}^{m} z_{i j} s^{l}{ }_{i j}+ \\
& \sum_{l=1}^{L} \sum_{j=l i=1}^{n} \sum_{i=1}^{m} z^{l}{ }_{i j} h_{i j}{ }_{i j} / 2+\sum_{i=1}^{m} \sum_{l=}^{L} \sum_{j=1}^{n} p d_{i j} z^{l}{ }_{j}\left(t^{l}{ }_{j}-t^{* l}{ }_{j}\right) g^{l}{ }_{j}+\sum_{l=1}^{L} \sum_{j=1}^{n} t_{j}{ }_{j} s^{* l}{ }_{j}=1
\end{aligned}
$$

In order to find the solution of the formulated mixed integer program model has been solved by the employing AMPL with Bonmin and Couenne. The program consists of two main parts; the main module containing the actual program and the data file containing data of the various parameters. The program was executed on a Pentium IV personal machine with a $1.73 \mathrm{GHz}$ processor and 2.0 GB RAM.

\subsection{Result discussion}

In order to analyze the effectiveness of the proposed models, a numerical example has been considered. It is assume that a vendor has 7 locations set, with 2 productions forecast for 2 retailers. The deterministic demand of unit products for retailers are $(1700,1400)$ and $(1800,1400)$, penalty cost of per unit in $(\$$.$) products for retailers are (0.10,0.60)$ and $(0.25,0.40)$ respectively. Further, Table 2 . describes additional information regarding the parameters for MIP models. 


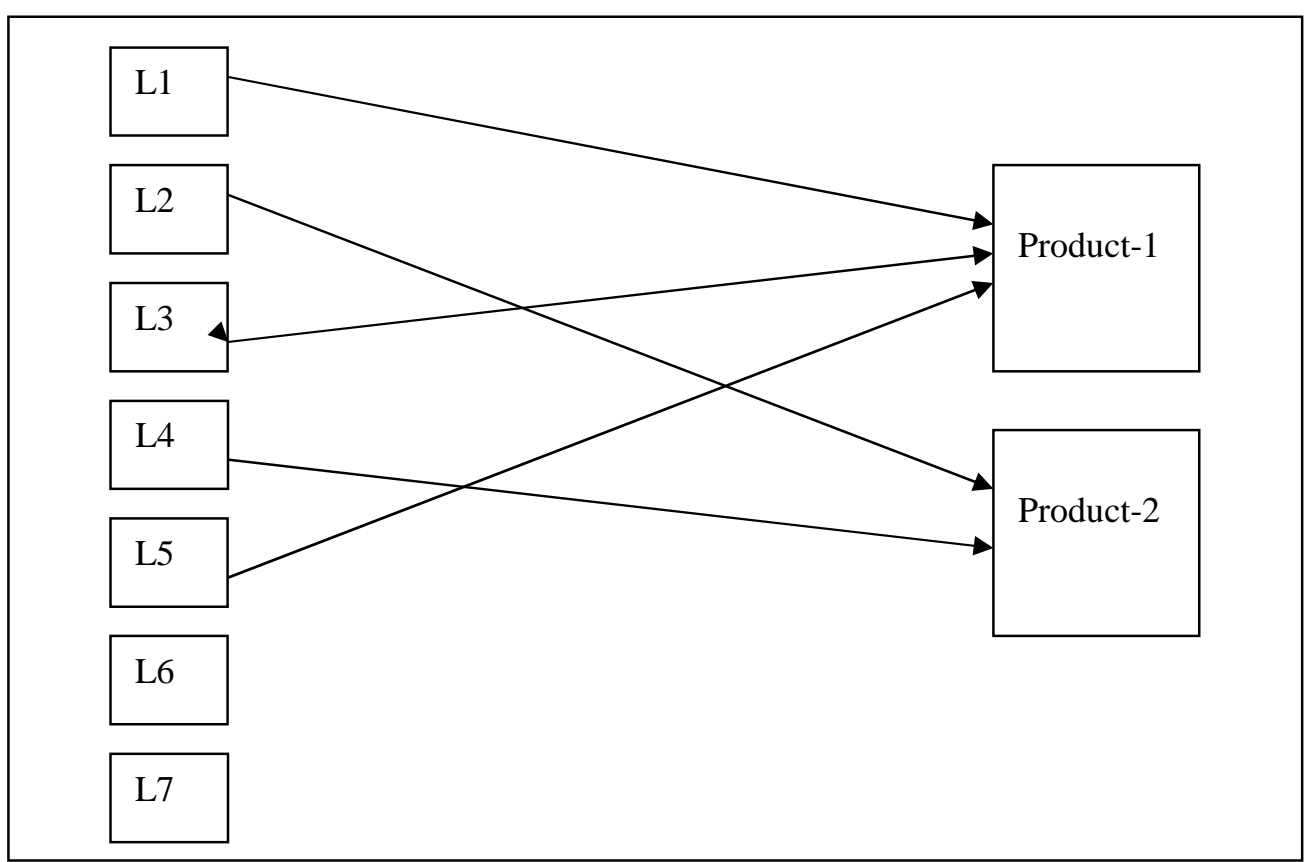

Fig. 3. Allocations for retailer-1 by (MIP) models

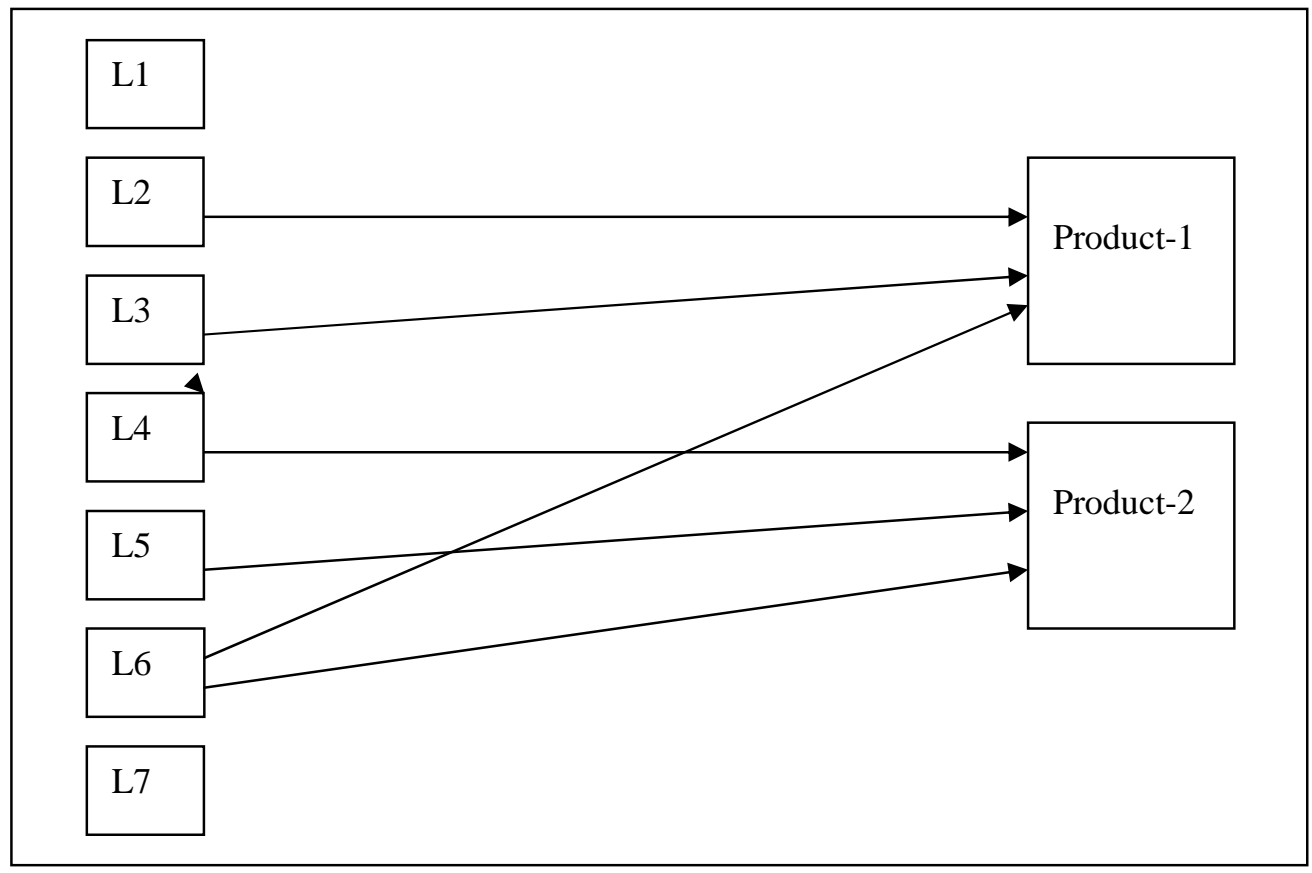

Fig. 4. Allocations for retailer-2 by (MIP) models 


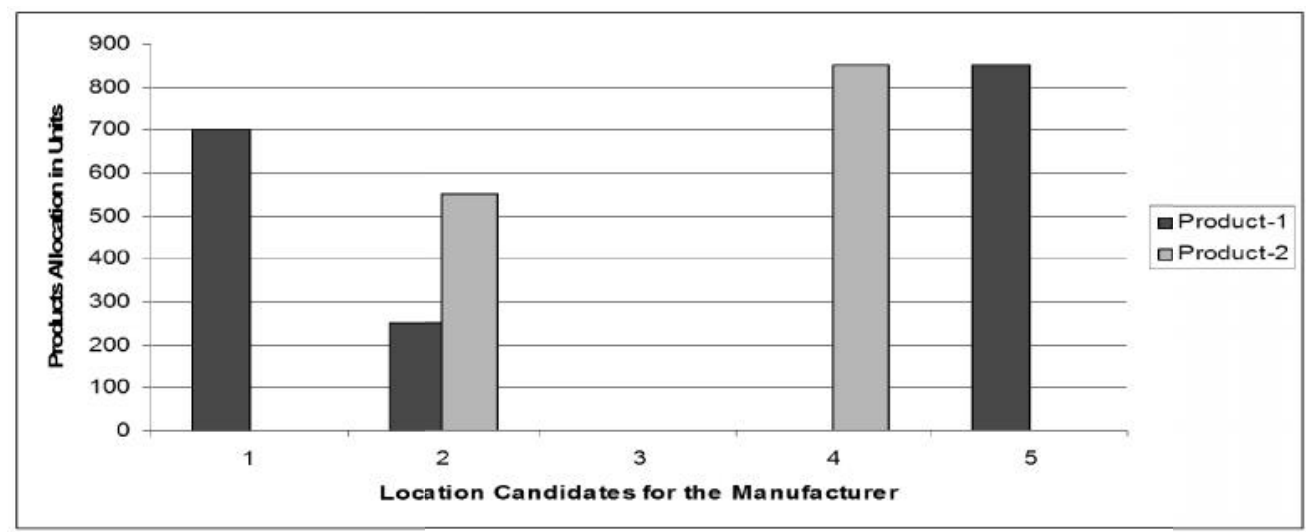

Fig. 5. Demand of different products at different locations for retailer-1 by MIP

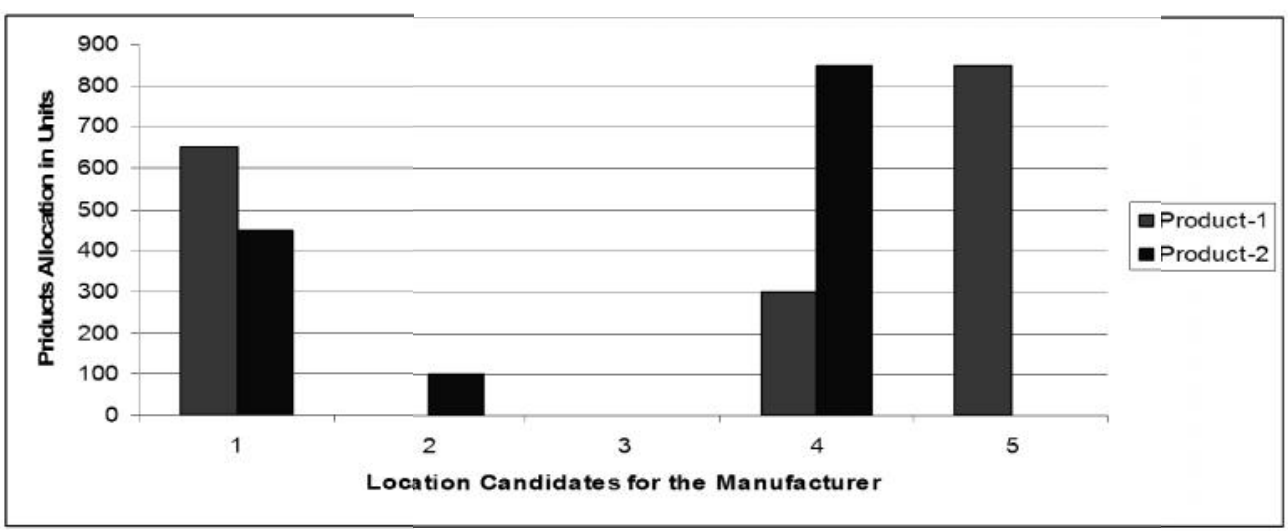

Fig. 6. Demand of different products at different locations for retailer-2 by MIP

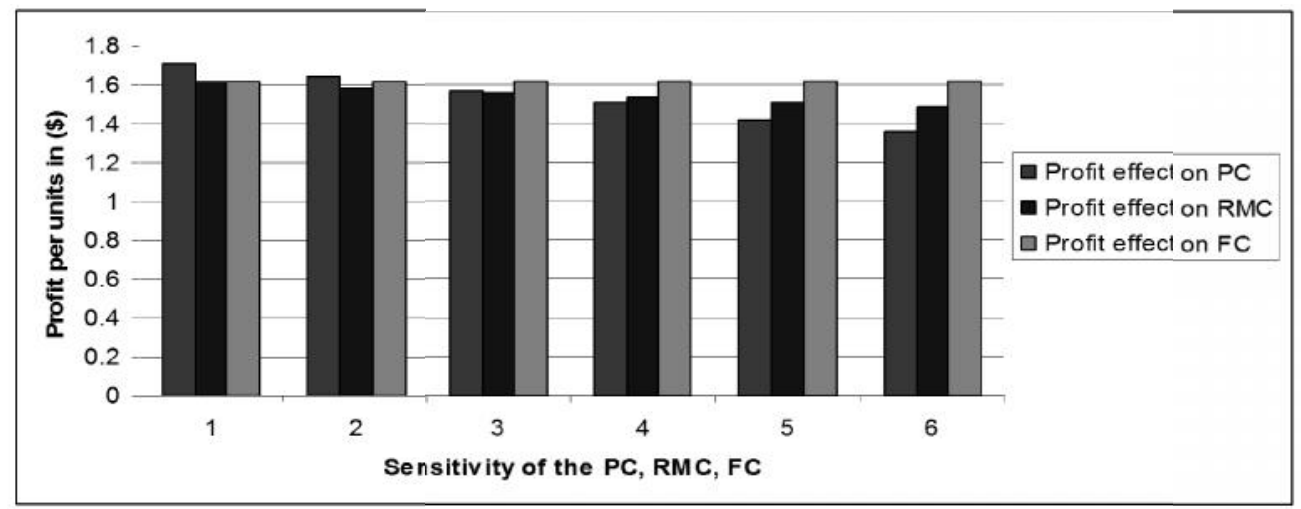

Fig. 7. Sensitivity analysis of profit effect on production cost (PC); raw material cost (RMC) and fixed cost (FC).

In order to observe the effect of the key parameters six sets of the vendor's opening costs with same average value such as $(6000,4000,5000,3000,5000),(4000,4000,5000$, 
4000, 6000), (6000, 4000, 4000, 7000, 2000), (5000, 6000, 4000, 5000, 3000), (5000, $3000,6000,6000,3000)$ and $(5000,3000,7000,2000,6000)$ are considered, while all other remaining parameters unchanged as it is shown in Table 2. are included. Finally, in order to estimate the effect of the sensitivity of production cost, fixed opening cost and raw material price parameter we employ sensitivity on these costs of different location. It is assumed that the production cost of the manufacturer located at six locations are (885, $935,985,1035,1085,1135)$, fixed opening cost of the manufacturer located at six locations are $(330,380,430,480,530,580)$ and raw material price of the manufacturer located at six locations are $(180,230,280,330,380,430)$ while all other remaining parameters unchanged.

\section{Conclusion}

In this study, an MIP based model is developed for the integrated supply chain network and the model is solved by AMPL. The formulated model simultaneously maximizes the difference between return and investment. Some of the significance findings can be summarized as follows:

Firstly, describe the optimum allocation of different products for both retailers. From the distribution pattern of different products, it is clear that MIP provides the optimal locations of the manufacturer for retailer-1 are 1,2,3,4 and 5. The optimal locations are achieved MIP models of the manufacturer for retailer-2 is 2, 3, 4, 5 and 6 . Therefore, from the distribution of different products by MIP models, it is apparently recommended that manufacturer-7 is not remained optimal for both retailer-1 and 2. Figures 5 and 6 describe that manufacturer-3 is not anyhow optimum for both retailer- 1 and 2 for all two products. It has observed that the selling price of eggs and chicken fluctuate depending on the natural calamities. Moreover, from the sensitivity analysis of the production cost and raw material cost, it is concluded that production cost and raw material cost is one of the momentous factors to increase and decrease the profit of a manufacturer. Further, the production cost and raw material cost has negative influence on the total profit. The poultry industry in Bangladesh is very diverse. The production of layer chicken is characterized by large-scale, intensive, commercial production systems with modern technology and imported hybrids. However, it faces a number of challenges. For the commercial layer chicken sector, its main concern would be the threat from global competition, because it is a high- cost producer by world standards. Therefore, MIP model could be one of the relevant approaches in a logistic model which seeks to find the optimum manufacturer as well as optimum distribution with profit maximization and cost minimization.

\section{REFERENCES}

[1] Canel, C., Khumawala, B. M. (1997), Multi-period international facilities location: an algorithm and application, International Journal of Production Research, 35 (7), 1891-1910.

[2] Canel, C., Khumawala, B. M. (2001), International facilities location: a heuristic procedure for the dynamic incapacitated problem, International Journal of Production Research, 39 (17), 3975-4000.

[3] Cohen, M.A., Lee, H.L. (1988), Strategic analysis of integrated production-distribution systems: Models and methods, Operations Research, 36 (2), 216-228. 
[4] Cohen, M.A., Lee, H.L. (1989), Resource deployment analysis of global manufacturing and distribution networks, Journal of Manufacturing and Operations Management, 2, 81-104.

[5] Pirkul, H., Jayaraman, V. (1996), Production, transportation, and distribution planning in a multicommodity tri-echelon system, Transportation Science, 30 (4), 291-302.

[6] Fumero, F., Vercellis, C. (1991), Synchronized development of production, inventory, and distribution schedules, Transportation Science, 33 (3), 330-340.

[7] Chandra P., Fisher M.L. (1994), Coordination of production and distribution planning, European Journal of Operational Research, 72 (3), 503-517.

[8] Qin, Y., Tang, H. and Guo, C. (2007), Channel coordination and volume discounts with price-sensitive demand, Int. J. Production Economics, Vol. 105, 43-53.

[9] Uddin, M. F., and Sano, K. (2010), Mixed Integer Linear Fraction Programming for Supply Integrated Supply Chain Network design and Optimization, International Journal of Business and Economics, Vol. 2, No. 1, pp. 57-70.

[10] Pourakbar, M., Farahani, R. Z. and Asgari, N. (2007), A joint economic lot-size model for an integrated supply network using genetic algorithm, Applied Mathematics and Computation, Vol. 189, 583-596.

[11] Wu, K.S. and Yen, H.F. (2009), On A note on the economic lot size of the integrated vendor buyer inventory system derived without derivatives, International journal of Information and Management Sciences, Vol. 20, 217-223.

[12] Zavanella, L. and Zanoni, S. A. (2009), One vendor multi-buyer integrated production inventory model: The consignment stock case, Int. J. Production Economics, Vol. 118, 225-232.

[13] Sajadieh, M.S. and Jokar, M.R.A. (2009), Optimizing shipment, ordering and pricing policies in a twostage supply chain with price sensitive demand, Transportation Research Part E, Vol. 45, 564-571.

[14] Qi, X., Bard, J.F. and Yu, G. (2004), Supply chain coordination with demand disruptions, Omega, Vol.32, 301-312.

[15] Akter, Afia and Uddin, Salah (2009), Bangladesh Poultry Industry, Journal of Business and Technology (Dhaka), Vol.4, No.2, pp.97-112.

[16] Islam, Uddin and Alam (2014), Analyze challenges and prospects of poultry industry in Bangladesh, European Journal of Business and Management, (Online), Vol.6, No.7

[17] Andrew, D. (2008), Jonathan, K. and Colin, P. Village chickens in household and national economies, World development report. 